\title{
Ten-Year Clinical Experience on Chylothorax after Cardiovascular Surgery
}

\author{
Doğan Kahraman, MD, ${ }^{1}$ Gökhan Keskin, MD, ${ }^{2}$ Emced Khalil, ${ }^{3}$ Omer Faruk Dogan, $\mathrm{MD}^{4}$ \\ ${ }^{1}$ Department of Cardiovascular Surgery, Gaziantep University School of Medicine, Gaziantep, Turkey ; ${ }^{2}$ Department of Cardiology, \\ Amasya University School of Medicine, Amasya, Turkey; ${ }^{3}$ Department of Cardiovascular Surgery, Ordu University Research and \\ Training Hospital, Ordu, Turkey; ${ }^{4}$ Department of Cardiovascular Surgery, Kafkas University School of Medicine, Kars, Turkey
}

\section{ABSTRACT}

Background: Chylothorax or pseudo-chylothorax is a serious complication after adult and pediatric cardiac surgery. This study presents our 10-year clinical experience of chylothorax after cardiac surgery.

Methods: Between January 2008 and February 2019, 4896 cardiovascular surgeries were performed in 2 tertiary clinics, with 416 patients in the pediatric age group $(8.4 \%)$. Chylothorax and pseudo-chylothorax were detected in 47 patients (22 adult and 20 pediatric patients, $4.8 \%$ ). Pseudo-chylothorax was seen in 5 adult patients. In 27 patients, a pleural effusion developed on the left side (64.2\%). Quantities of chylomicron in pleural effusion were significant in all patients. In addition, protein and lactate dehydrogenase levels were $>2.9 \mathrm{~g} / \mathrm{dL}$. The cholesterol level in the pleural effusion was $>2.49 \mathrm{mmol} / \mathrm{L}$ in all patients. The mean latency period was 8 days (range 3.1 to 63.1 ). For the management of chylothorax, somatostatin or octreotide as a somatostatin analog was administered in 23 patients (15 adult and 8 pediatric) in the intensive care unit. Somatostatin or octreotide was administered intravenously or subcutaneously at a dose of 0.3 to $4 \mu \mathrm{g} /\left(\mathrm{kg} \cdot \mathrm{h}^{-1}\right)$. We used dexamethasone as a steroid combined with somatostatin in patients who were resistant to medical treatment before pleurodesis or ductus closure. Classic chemical pleurodesis combined with fibrin glue was performed in 11 patients ( 8 adult and 3 pediatric). Surgical duct ligation, as the last option, was performed in 7 patients.

Results: No mortality or morbidity was observed. Chylothorax improved with the medical approach in 23 patients within $24.2 \pm 11.3$ days (48.9\%). We successfully performed the pleurodesis procedure using fibrin glue in addition to the classic method. The mean duration of conservative treatment was 27.1 days (range 11 to 39). After discharge from the hospital, 2 children had recurrence of chylothorax, and the ductus thoracicus was surgically ligated. No complication was seen during or after ductus ligation.

Conclusions: According to our clinical experience, chylothorax is not an extremely rare complication after cardiac surgery in pediatric cardiovascular surgery. A number of patients with chylothorax may be treated medically and with diet

Received fuly 5, 2019; accepted October 23, 2019.

Correspondence: Omer Faruk Dogan, Suleyman Demirel Bulvari, Huzurevleri Mahallesi Elit Plaza 8/8, 01360, Çukurova, Adana, Turkey(e-mail: ofdogan@ bacettepe.edu.tr). adjustment. Medical treatment including steroid administration may be the first treatment strategy immediately after diagnosis. Classic chemical pleurodesis combined with fibrin glue may be applied in the early stages. Surgical ligation of the ductus thoracicus should be considered the last treatment option.

\section{INTRODUCTION}

The milky appearance of the pleural fluid was first diagnosed in 1633 by Bartolet [Doğan 2004]. A milky, serous, or transudative chylous pleural effusion has been described in patients after cardiac surgery. The rate of chylothorax after cardiothoracic procedures has been reported as $2.4 \%$ to $5.4 \%$ in patients who have undergone cardiovascular surgery [Doğan 2004; Hillerdal 1997; Yıldız 2015; Kara 2014]. It has been detected more frequently in the pediatric age group compared with adults [Sapmaz 2018]. The classic appearance of chylothorax is milky [Doğan 2004; Hillerdal 1997; Yildiz 2015], but appearance of chylothorax and pseudochylothorax may be serous or transudative [Sapmaz 2018; Cannizzaro 2006; Yeh 2013]. The presence of chylomicrons in pleural effusion is considered the gold standard in diagnosing chylothorax and pseudo-chylothorax [Doğan 2004; Hillerdal 1997; Yildiz 2015; Kara 2014; Sapmaz 2018; Cannizzaro 2006; Yeh 2013; Chan 2005]. If the triglyceride (TG) level of a pleural effusion is $<2.77 \mathrm{mmol} / \mathrm{L}$, the diagnosis of chylothorax may be excluded [Sapmaz 2018]. Chylothorax may cause nutritional deficiencies or infection and hence is associated with morbidity and mortality [Yeh 2013; Chan 2005].

Respiratory symptoms are the most common clinical condition in these patients [Beghetti 2000]. Malnutrition can be seen due to the loss of proteins and lipids [Büttiker 1999; Nath 2009]. Spontaneous chylothorax has been described in association with cancer in the mediastinum, intractable infections, and some inflammatory diseases [Chan 2005; Beghetti 2000; Büttiker 1999; Nath 2009; Jenkins 2002; Merrigan 1997]. It has also been reported after coronary artery bypass grafting (CABG) surgery in rare patients owing to laceration of the thoracic duct [Merrigan 1997; Ismail 2014]. Chylothorax has been defined after surgery of single ventricle, aortic coarctation, aortic aneurysm surgery, closure of the patent ductus arteriosus, etc. [Merrigan 1997; Ismail 2014; Heffner 2002].

This study presents our 10-year clinical experience in chylothorax and pseudo-chylothorax after cardiovascular surgery. 
Table 1. Type of Cardiothoracic Surgery in Children with Chylothorax*

\begin{tabular}{|c|c|c|c|c|c|c|c|}
\hline 1 & $8 \mathrm{mo}$ & $M$ & $A S D+P S$ & Total repair & 1.8 & 1870 & 19 \\
\hline 3 & $9 \mathrm{mo}$ & $\mathrm{F}$ & AVSD & Total repair & 10.5 & 1398 & 11 \\
\hline 4 & $56 d$ & $\mathrm{~F}$ & $V S D+A S D$ & Total correction & 2.1 & 1890 & 22 \\
\hline 6 & $3 \mathrm{mo}$ & $\mathrm{F}$ & AVSD & Repair & 1.4 & 1900 & 19 \\
\hline 7 & $8 \mathrm{mo}$ & $M$ & Large PDA & Repair & 5.9 & 2100 (bilateral) & 29 \\
\hline 8 & $4 d$ & $\mathrm{~F}$ & TAPVR & Repair & 14.7 & 4670 & 14 \\
\hline 9 & $3.2 y$ & $\mathrm{~F}$ & PDA + coarctation & Ligation + repair & 1.6 & 1960 & 17 \\
\hline 10 & $49 d$ & $M$ & Coarctation + PDA & Repair & 8.8 & 4300 & 9 \\
\hline 14 & 8.1 y & $M$ & $A S D+V S D$ & Repair & 2.3 & 7100 & 17 \\
\hline 15 & $3.2 \mathrm{y}$ & $\mathrm{F}$ & Coarctation & Repair & 1.9 & 2010 & 13 \\
\hline 16 & 4.7 y & $M$ & $\mathrm{TA}+\mathrm{ASD}$ & Glenn & 18.2 & 5100 & 16 \\
\hline 17 & 4.2 y & $M$ & TOF & Total repair & 9.6 & 3050 & 17 \\
\hline 18 & $3.6 y$ & $\mathrm{~F}$ & $T A+A S D+V S D$ & EC Fontan & 6.3 & 4200 & 14 \\
\hline 19 & $1.7 y$ & $M$ & $\mathrm{TOF}+\mathrm{PFO}$ & Repair & 4.4 & 5900 & 16 \\
\hline 20 & $5.6 y$ & $M$ & $\mathrm{PDA}+\mathrm{ASD}+\mathrm{VSD}$ & Repair & 5.3 & 4300 & 18 \\
\hline
\end{tabular}

*ASD indicates atrial septal defect; AVSD, atrioventricular septal defect; EC, extracardiac; HAA, hypoplastic aortic arch; PDA, patent ductus arteriosus; PFO, patent foramen ovale; TA, tricuspid atresia; TAPVR, total anomalies of pulmonary venous return; TGA, transposition of great arteries; TOF, tetralogy of Fallot; VSD, ventricular septal defect.

\section{METHODS}

A total of 4896 cardiovascular surgeries were performed between January 2008 and February 2019. 416 patients were in the pediatric age group. Chylothorax $(n=42)$ and pseudochylothorax $(\mathrm{n}=5)$ were detected after cardiovascular operations in 47 patients, 20 in the pediatric age group. For the definitive diagnosis of chylothorax and pseudo-chylothorax, the pleural effusion was biochemically analyzed for each patient. If lactate dehydrogenase was less than two-thirds of the upper limit of normal serum and cholesterol level was $<2.5 \mathrm{mmol} / \mathrm{L}$ in the pleural fluid, we classified the case as pseudo-chylothorax.

The rate of chylothorax in pediatric and adult patients was $4.8 \%$ and $0.6 \%$, respectively. According to our study results, chylothorax was more common in pediatric cardiovascular surgery $(P=.001)$. No pseudo-chylothorax was detected after pediatric cardiac operations. Pseudo-chylothorax after surgery was seen in the early period (the mean latent period was $2.1 \pm 0.9$ days (range 1 to 5 ). It was detected in only 5 adult patients $(0.1 \%)$. Patient characteristics and details on surgeries are summarized in Tables 1 and 2, respectively.
The mean age of patients was 48 years (range 1 day to 78 years). The rate of occurrence of chylothorax and pseudochylothorax after cardiothoracic surgery in children and adults after surgery was $0.95 \%$. In 27 patients, pleural effusion developed on the left side $(64.2 \%)$. In 8 patients, chylothorax was bilateral (19\%) (3 pediatric and 5 adult). Pseudo-chylothorax was detected unilaterally. According to the Heffner classification [Heffner 2002], the classic milky appearance of pleural effusion was seen in only $44 \%$ of patients. In the remaining patients (56\%), chylous effusions were exudative or transudative. The levels of cholesterol, protein, and lactate dehydrogenase in the aspirated pleural fluid were examined for each case. In 21 patients (14 adult and 7 pediatric), chylothorax developed in the early stages after surgery (within 4 days).

The main complaints of patients were chest pain, early fatigue, and respiratory problems such as dyspnea (minimum 14 days; maximum 6.4 months). In 18 patients, chylous effusion was exudative $(38.2 \%)$. A transudative characteristic was seen in 8 patients (17\%). The biochemical analyses showed that the triglyceride level of the effusion ranged from 1.8 to $19.4 \mathrm{mmol} / \mathrm{L}$. The protein content was 2.1 to $5.9 \mathrm{~g} / \mathrm{dL}$. The simultaneous blood analysis demonstrated that the mean triglyceride and cholesterol levels were 4.3 and $5.6 \mathrm{mmol} / \mathrm{L}$, 
Table 2. Type of Cardiothoracic Surgery in Adults with Chylothorax*

\begin{tabular}{lcccccc}
\hline Patient & Age $(\mathrm{yr})$ & Cardiovascular pathology & Surgery & TG (mmol/l) & Total drainage (mL) & Duration (d) \\
\hline 11 & $59 \pm 9.4$ & CAD & Redo CABG & $14.6 \pm 13.9$ & 6700 & $24 \pm 7.9$ \\
7 & $67 \pm 11.3$ & Type I AD & Repair & $9.1 \pm 11.9$ & 3870 & $15 \pm 6.9$ \\
3 & $34 \pm 8.9$ & AS & AVR & $16.1 \pm 6.2$ & 4480 & $12 \pm 6.9$ \\
6 & $61 \pm 12.4$ & TAA & Repair & $19.4 \pm 11.2$ & 7600 & $18 \pm 6.9$ \\
\hline
\end{tabular}

*Data are $n$ or mean \pm SD unless noted otherwise. AD indicates aortic dissection; AS, aortic valve stenosis; AVR, aortic valve replacement; CABG, coronary artery bypass graft; CAD indicates coronary artery disease; TAA, thoracoabdominal aneurysm.

respectively. The mean total protein level was $316 \mathrm{mmol} / \mathrm{L}$. Microscopic evaluations showed that all samples had lymphocyte predominance.

The mean latency period of both groups after discharge from hospital was 32 days (range 14 to 189). In pediatric patients, median time to diagnosis of chylothorax was 6 days (range 1 to 30 ) after surgery. The median time for diagnosing chylothorax was 8 days (range 1 to 58 ) in the pediatric group and 6 days (range 1 to 176) in the adult group.

A chest roentgenogram (Figure 1), thoracic computed tomography scan (Figure 2), or ultrasonography (Figure 3) was used for confirming fluid accumulation. The pleural fluid was aspirated using a syringe for laboratory analyses before thoracostomy (Figure 4). Then, tube thoracostomy was performed immediately after aspiration of pleural fluid in all patients. The mean amount of effusion on the first day was $2750 \mathrm{~mL}$ (range 1450 to 5600) in adults. In the pediatric group, the amount of chylous effusion was $180 \mathrm{~mL}$ (range 160 to 570).

\section{Data Analysis}

Data are described as frequencies and medians with ranges as appropriate. The incidence of chylothorax was calculated together with $95 \%$ confidence intervals (CIs). The duration and volume of chylous drainage were sought using mixed linear regression analysis for repeated or serial measurements.

\section{Treatment Protocols}

According to the our institutional protocol, all patients with chylothorax were hospitalized in the intensive care unit (ICU) for administration of somatostatin or octreotide after consultation with the pediatrician. Intravenous antibiotics were administered to each patient in the ICU after consultation by a pediatrician. Somatostatin or octreotide was given when the amount of pleural drainage did not decrease to a volume of $<3 \mathrm{~mL} /\left(\mathrm{kg} \cdot \mathrm{d}^{-1}\right)$ after keeping patients nil per os for 5 days, followed by total parenteral nutrition (TPN). For patients with high-volume drainage $\left[\geq 5 \mathrm{~mL} /\left(\mathrm{kg} \cdot \mathrm{d}^{-1}\right)\right]$, oral nutrition was stopped, and TPN was administered. Intravenous or subcutaneous somatostatin was administered for treating TPN-resistant patients. TPN included a lowfat diet rich in medium-chain fatty acids. Calorie intake was restricted to $1500 \mathrm{kcal} /$ day in adult patients and in pediatric patients according to their characteristics such as weight and time of diagnosis.
We continued intravenous somatostatin for 1 to 3 days for adult patients. We used subcutaneous octreotide in adult cases with chylous effusion because it has a longer half-life and a higher potency. In the pediatric group, intravenous somatostatin was administered for 5 to 7 days in the ICU. Subcutaneous octreotide (100 units), 3 times a day, was started for all adult patients. In pediatric patients, the dose of somatostatin was 10 to 15 units 2 times a day intravenously. The drainage tube was removed when the amount of chylous effusion decreased to $<0.5$ to $1 \mathrm{~mL} / \mathrm{kg}$.

We know that steroids, as an anti-inflammatory agent, decrease vascular tone and inhibit volume loading in the ductus thoracicus. In intractable patients, the use of somatostatin or octreotide combined with steroids significantly reduced the amount of chest tube drainage. Therefore, dexamethasone, as a steroid, was used in patients resistant to the standard medical treatment. In 6 to 8 days, the amount of drainage [expressed as mean \pm standard deviation (SD)], decreased to $250 \pm 110 \mathrm{~mL} / \mathrm{d}$ in adult patients $(\mathrm{n}=19)$ and $45 \pm 22.4 \mathrm{~mL} / \mathrm{d}$ in pediatric patients $(\mathrm{n}=17)$. The amount of chylous drainage was $>5 \mathrm{~mL} /(\mathrm{kg} \cdot \mathrm{d}-1)$ despite our management protocols in 9 patients ( 6 pediatric and 3 adult), and we continued steroid administration for 5 to 7 additional days. Therefore, the mean duration of steroid administration was $12.3 \pm 5.4$ days (range 9 to 17 ).

If the amount of pleural effusion was $>200 \mathrm{~mL} / \mathrm{d}$ in adults and $>50 \mathrm{~mL} / \mathrm{d}$ in children 3 weeks after tube thoracostomy, we decided on pleurodesis for treating the chylothorax. Pleurodesis was performed using $25 \mathrm{~mL}$ of $7.5 \%$ povidoneiodine diluted with $25 \mathrm{~mL}$ of $0.9 \%$ saline and $10 \mathrm{~mL}$ of $2 \%$ lidocaine in the 8 adult patients. In the 3 pediatric patients, pleurodesis was performed using 3 to $5 \mathrm{~mL}$ of $7.5 \%$ povidone-iodine diluted with $5 \mathrm{~mL}$ of $0.9 \%$ saline and 1 to $3 \mathrm{~mL}$ of $2 \%$ lidocaine. The drain was clamped, and the patients were rotated to the contralateral side. The clamp was released 2 to 4 hours later. The amount of drainage from the thorax was noted.

If this method of pleurodesis failed, we performed pleurodesis using a fibrin glue. This method has been described as an easy procedure and seems to be almost as effective for treating the chylous leak as direct ligation of the thoracic duct [Stenz] 1983; Oishi 2017]. The surgical closure of the ductus thoracicus is associated with challenges and morbidities because it requires thoracotomy and general anesthesia. Therefore, we 


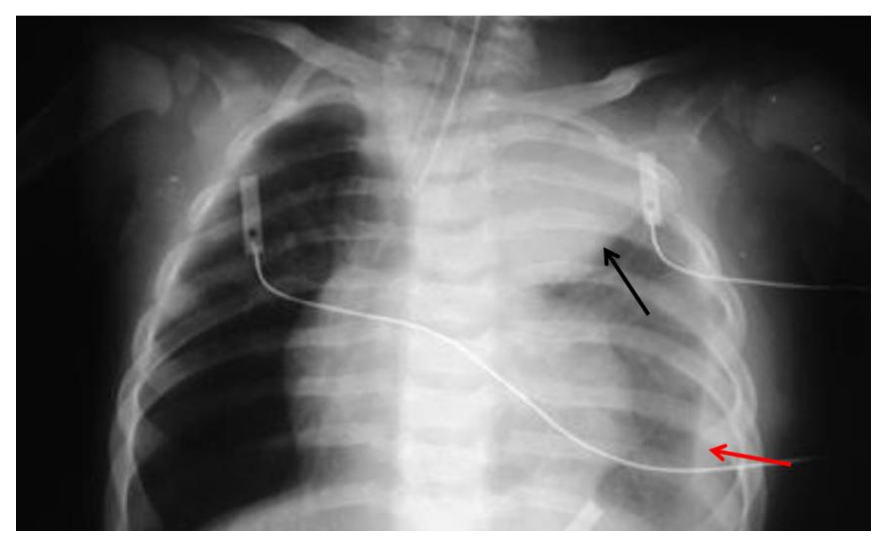

Figure 1. Left-side chylothorax and perigraft seroma formation after systemic-to-pulmonary artery shunt using a polytetrafluoroethylene graft in a 3-month-old patient with tricuspid atresia, patent ductus arteriosus, and atrial septal defect. Black and red arrows indicate perigraft seroma and pleural effusion, respectively.

chose fibrin glue application for redo pleurodesis as a new conservative treatment in patients with persistent chylous leakage. Beriplast P Combi (CSL Behring, Marburg, Germany) was used to decrease the intrapleural space and achieve strong intrapleural adhesions. Using the chest tube, 15 to $20 \mathrm{~mL}$ of fibrinogen was injected into the pleural space. After the procedure, the tube was flushed with 25 to $30 \mathrm{~mL}$ of saline solution. Immediately after these procedures, $25 \mathrm{~mL}$ of thrombin solution was injected, and the chest tube was flushed with 30 $\mathrm{mL}$ of saline solution. The drain was removed $24 \mathrm{~h}$ later if the amount of pleural effusion was $<50 \mathrm{~mL}$ in adults and $<10 \mathrm{~mL}$ in children depending on patient weight.

If chylothorax persisted 4 to 6 weeks later despite medical management, we performed ductus thoracicus ligation to shorten hospitalization and reduce the risk of mortality and morbidity.

Unfortunately, lymphangiography is difficult to perform in our center, and radiologists have little experience in cannulating a small duct in the foot, so no imaging modalities were used to determine the location of the chylous leakage. According to previous description of surgical techniques and anatomic location of the thoracic duct [Keceligil 2005], we used a right thoracotomy (the seventh intercostal space) in these patients. The ductus thoracicus was ligated successfully (3 pediatric and 4 adult). No difficulties were encountered during the adhesiolysis of the pleural cavity in patients who underwent surgical duct ligation.

\section{RESULTS}

No mortality or morbidity was observed. Chylothorax improved with the medical approach in 23 patients within $24.2 \pm 11.3$ days (48.9\%). We successfully performed the pleurodesis procedure using fibrin glue in addition to the classic method. The mean duration of conservative treatment was 27.1 days (range 11 to 39 ). After discharge from the hospital,

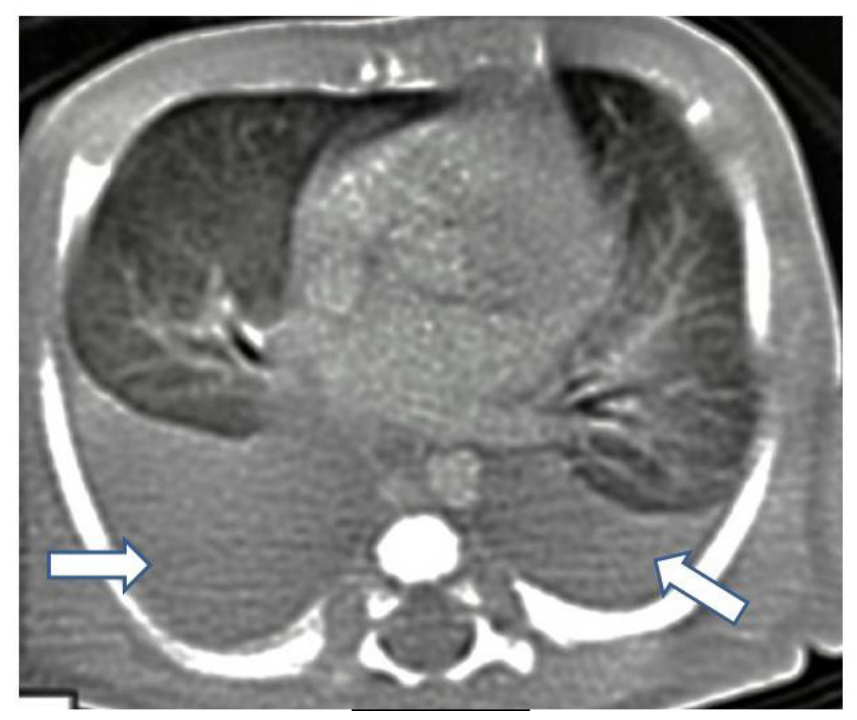

Figure 2. Bilateral chylothorax after the correction of total anomalous total venous connection in a pediatric patient. The pleural effusion is transudative with high chylomicron and protein levels. Arrows indicate bilateral pleural effusion.

2 children had recurrence of chylothorax. Therefore, the ductus thoracicus was surgically ligated. No complication was seen during or after ductus ligation.

\section{DISCUSSION}

The incidence of chylothorax after cardiovascular surgery was reported in $1 \%$ to $3.5 \%$ of patients, whereas the latest reported incidence rate was $5 \%$. The rate of chylothorax in our cases series is similar to that of previous publications. The classic appearance of chylothorax is milky [Doğan 2004; Hillerdal 1997; Y1ldiz 2015], but the appearance of chylothorax and pseudo-chylothorax may be serous or transudative, as we show in our series [Sapmaz 2018; Cannizzaro 2006; Yeh 2013]. The presence of chylomicrons in pleural effusion is considered the gold standard in diagnosing chylothorax and pseudo-chylothorax [Doğan 2004; Hillerdal 1997; Yildiz 2015; Kara 2014; Sapmaz 2018; Cannizzaro 2006; Yeh 2013; Chan 2005].

The complexity of cardiovascular surgery and a pediatric age are the main factors for the development of chylothorax or pseudo-chylothorax [Doğan 2004; Hillerdal 1997; Yıldız 2015; Kara 2014; Sapmaz 2018; Cannizzaro 2006]. The management of chylothorax includes the drainage of pleural effusion, balancing of nutrition (oral feeding or TPN), and somatostatin or octreotide administration, which are acceptable standard protocols in many centers [Doğan 2004; Hillerdal 1997; Yıldız 2015; Kara 2014; Yeh 2013; Chan 2005; Beghetti 2000; Büttiker 1999]. Previous reports proposed pleurodesis or ductus thoracicus ligation as a last option in selected patients who did not respond to medical management [Jenkins 2002; Merrigan 1997; Ismail 2014; Heffner 2002; Chan 2006]. 


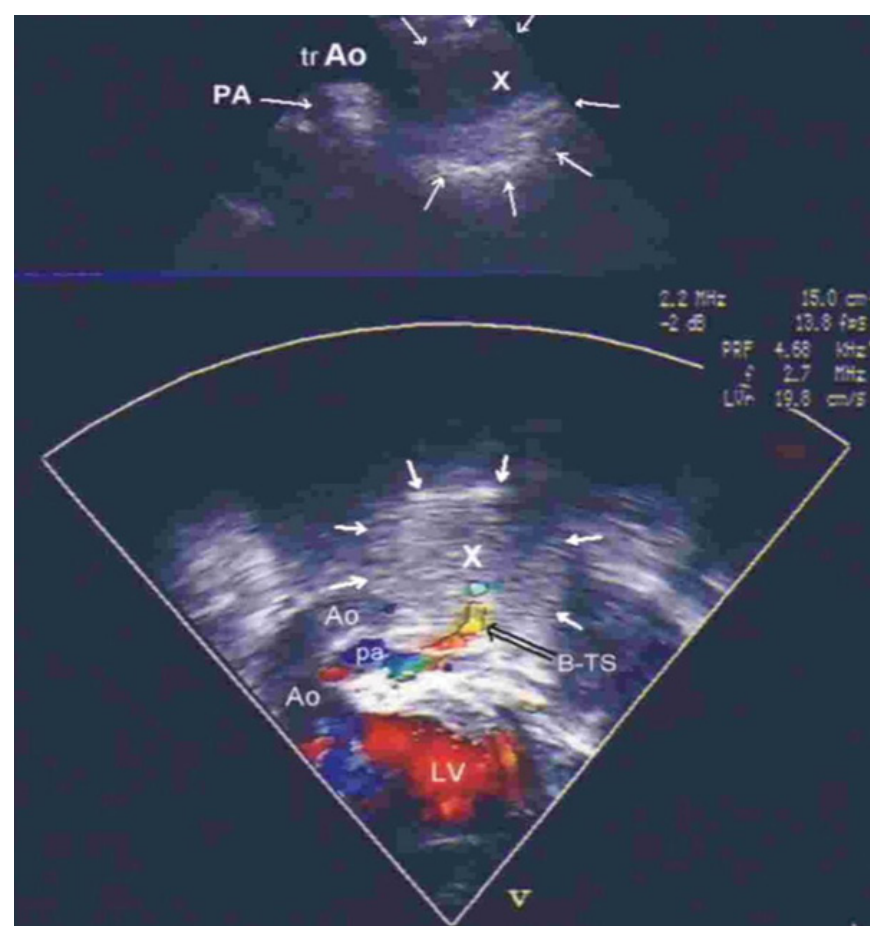

Figure 3. Echocardiographic image of perigraft seroma and pleural effusion in a female infant with tetralogy of Fallot having hypoplastic pulmonary arteries after systemic-to-pulmonary artery shunt. White arrowheads indicate perigraft seroma. This figure demonstrates the well-functioning shunt material. PA, pulmonary artery; trAo, transverse aorta; LV, left ventricle.

In previous reports, subcutaneous octreotide or intravenous somatostatin combined with medical treatment was suggested because these drugs reduce pancreatic and intestinal secretions [Y1ldız 2015; Kara 2014; Sapmaz 2018; Cannizzaro 2006; Yeh 2013; Chan 2005; Beghetti 2000; Büttiker 1999; Nath 2009]. Studies have shown that this adjuvant therapy additionally decreases hepatic venous pressure and reduces splanchnic blood flow [Heffner 2002]. In contrast to previous publications, some authors have suggested that the use of somatostatin or octreotide is not effective for treating chylothorax [Stenzl 1983; Oishi 2017]. However, previous reports clearly demonstrated the effectiveness of somatostatin to treat postoperative chylothorax that was resistant to medical management [Doğan 2004; Yıldız 2015; Cannizzaro 2006; Keceligil 2005].

Many side effects of somatostatin, such as bradycardia, diarrhea, nausea, constipation, headache, and pancreatitis, have been described [Beghetti 2000; Büttiker 1999; Nath 2009; Jenkins 2002; Merrigan 1997; Ismail 2014; Heffner 2002; Chan 2006]. In addition, other side effects that occurred in $1 \%$ to $4 \%$ of patients included edema, flushing, visual disturbance, hepatitis, gastrointestinal bleeding, gastric or peptic ulcer, chest pain, thrombophlebitis, congestive heart failure, high blood pressure, neuritis, and anemia. These side effects occur because somatostatin causes the vasoconstriction of splanchnic vessels and hence reduces gastric, pancreatic, and

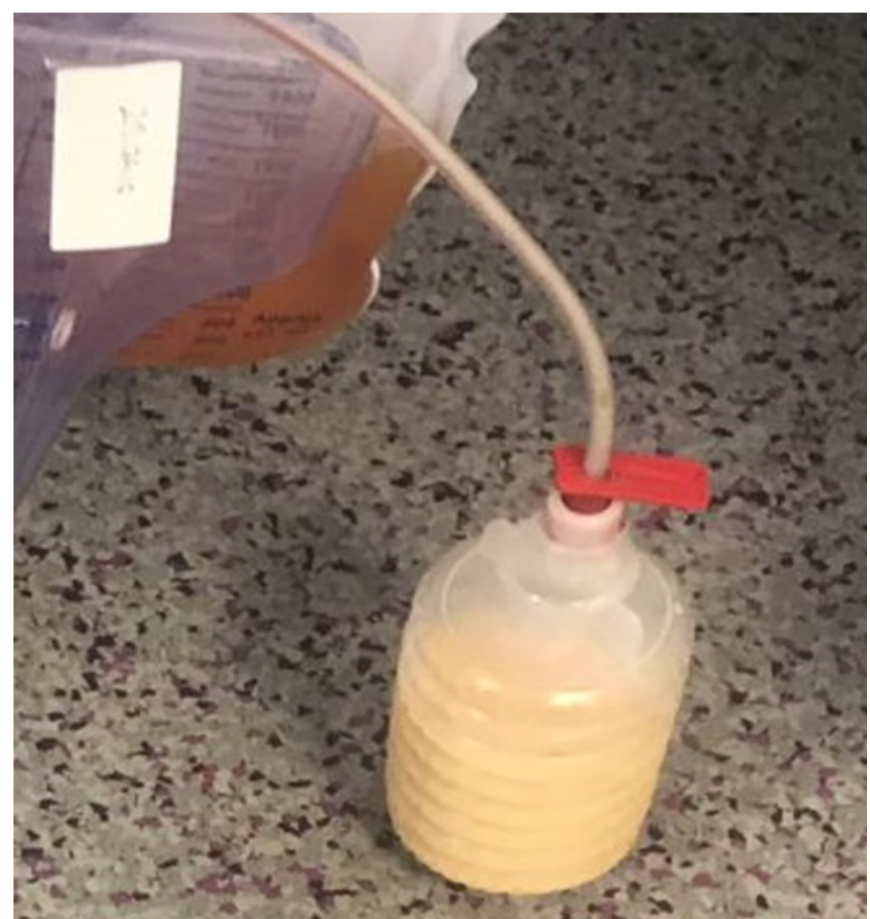

Figure 4. Classic milky appearance of chylous pleural effusion in an infant who underwent aortic coarctation repair.

intestinal secretions [Sersar 2011; Liu 2005]. Therefore, the dose of somatostatin has been suggested as $0.1 \mathrm{mg}$ every $8 \mathrm{~h}$ for treating chylothorax via subcutaneous injection or intravenous administration [Sapmaz 2018; Chan 2005]. Because of the importance of somatostatin's side effects, we closely followed all patients in the ICU during the treatment period.

Our study indicates that the rate of chylothorax is more common in pediatric cardiac surgery patients. No standardized protocol has been described in the literature for treating patients with chylothorax. Thus, we present the clinical results of our protocols including medication and surgical approach as a last option after diagnosis of chylothorax in a limited number of patients in this retrospective study. The laboratory analyses of chylothorax and pseudo-chylothorax showed that the samples of pleural effusions had high triglyceride and protein levels in all patients. The biochemical analyses of pleural effusions of our patients demonstrated that the triglyceride level of pleural effusions ranged from 1.8 to 19.4 $\mathrm{mmol} / \mathrm{L}$, and the mean protein value was $3.8 \pm 5.9 \mathrm{~g} / \mathrm{dL}$ in exudative and transudative pleural effusions. We saw pseudo-chylothorax in only 5 adult patients $(0.1 \%)$, but the same treatment protocol was effective in this group.

Surgery is considered when a chylous effusion does not decrease despite 4 to 6 weeks of optimal conservative management combined with dietary fat restriction or when the average daily chylous effusion is $>100 \mathrm{~mL}$ for $>5$ days [Ismail 2014; Heffner 2002; Oishi 2017].

In our study, we suggest steroids (dexamethasone; daily dose of $1 \mathrm{mg} / \mathrm{kg}$ ) as an additional medication with or without 
pleurodesis in patients resistant to the suggested management before ductus thoracicus ligation, patients who have chylous leakage $>3$ to $5 \mathrm{~mL} / \mathrm{kg}$, or patients who have chylous drainage that lasts $>12$ days in either adults or children. We did not detect any side effect related to dexamethasone during the treatment period.

We also describe the use of fibrin glue for pleurodesis in pediatric and adult patients who are resistant to medical management. We saw a high success rate after fibrin glue application for pleurodesis before ductus thoracicus ligation.

Some authors have suggested pleuroperitoneal shunt as an alternative surgical treatment for managing chylothorax [Merrigan 1997; Ismail 2014; Heffner 2002]. Many treatment choices are available before surgery, inclucing as ductus thoracicus ligation or pleuroperitoneal shunt [Chan 2006; Stenzl 1983]. If medical management of chylothorax has failed for $\geq 28$ days, we propose ligation of ductus thoracicus to shorten hospitalization and reduce the risk of mortality and morbidity related to second surgery.

The early application of effective treatment methods may increase the success rate of conservative management. Steroid administration can prevent the loss of proteins, electrolytes, and lymphocytes. Intensive medication using a steroid may prevent the complications of pleurodesis or thoracic duct ligation. Further randomized controlled studies are required for confirming the effectiveness and proper dosage of these agents. No randomized study has evaluated the safety and efficacy of somatostatin combined with steroid administration in infants; a limited number of case reports are available [Chan 2006].

Case reports have shown total resolution of chylothorax in pediatric patients after medical treatment alone. However, some reports demonstrated the failure of somatostatin or octreotide administration. No consensus has been reached on the dosage and duration of somatostatin or octreotide treatment. Coulter [2004] reported the longest duration of somatostatin use (35 days) in infants with chylothorax. In an unresponsive case, OK-432 was also suggested [Chalret 2011]. Surgery has been suggested after 10 days of somatostatin use in patients with chylothorax by the some surgeons [Coulter 2004; Nair 2007; Tatar 2011]. Our study showed that somatostatin or octreotide in combination with steroids may be used as a safe and effective combination for treating chylothorax.

\section{Limitations}

The main limitation of our study is its retrospective nature, with a small number of pediatric and adult patients. We had no control group to compare steroid administration or the effectiveness of glue combination in redo pleurodesis. We propose further studies avoiding these limitations and comparing medical treatment strategies.

\section{Conclusions}

According to our experience, chylothorax and pseudochylothorax may develop in 0.1 to $5 \%$ of patients after cardiac surgery. Physicians should in keep in mind that chylous effusion may be transudative or exudative. Levels of chylomicrons,
TG, and cholesterol should be investigated for the definitive diagnosis. Medical management, diet, and administration of octreotide in combination with steroids have shown successful clinical results in a number of patients with chylothorax. The results of the present study show that the somatostatinsteroid combination is safe and effective in treating chylothorax. Before surgical closure of the ductus thoracicus, chemical pleurodesis with fibrin glue may be performed safely. We propose ligation of the thoracic duct as the last choice when conservative management and pleurodesis fail.

\section{ACKNOWLEDGEMENT}

The authors would like to thank Dietetician Dilek Dogan for patients, dietetic consultation, and her suggestions for feeding procedures in the ICU.

\section{REFERENCES}

Beghetti M, La Scala G, Belli D, Bugmann P, Kalangos A, Le Coultre C. Etiology and management of pediatric chylothorax. J Pediatr 2000;136:653-658.

Büttiker V, Fanconi S, Burger R. Chylothorax in children: Guidelines for diagnosis and management. Chest 1999;116:682-687.

Cannizzaro V, Frey B, Bernet-Buettiker V. The role of somatostatin in the treatment of persistent chylothorax in children. Eur J Cardiothorac Surg 2006;30:49-53.

Chalret du Rieu M, Baulieux J, Rode A, Mabrut JY. Management of postoperative chylothorax. J Visc Surg 2011;148:346-352.

Chan EH, Russell JL, Williams WG, Van Arsdell GS, Coles JG, McCrindle BW. Postoperative chylothorax after cardiothoracic surgery in children. Ann Thorac Surg 2005;80:1864-1870.

Chan SY, Lau W, Wong WH, Cheng LC, Chau AK, Cheung YF. Chylothorax in children after congenital heart surgery. Ann Thorac Surg 2006;82:1650-1656.

Coulter DM. Successful treatment with octreotide spontaneous of chylothorax in a premature infant. J Perinatol 2004;24:194-195.

Doğan R, Demircin M, Dogan OF, Kuzgun E. Effectiveness of somatostatin in the conservative management of chylothorax. Turk J Pediatr 2004;46:262-264.

Heffner JE, Sahn SA, Brown LK. Multilevel likelihood ratios for identifying exudative pleural effusions. Chest 2002;121:1916-1920.

Hillerdal G. Chylothorax and pseudochylothorax. Eur Respir J 1997;10:1157-1162.

Ismail SR, Kabbani MS, Najm HK, Shaath GA, Jijeh AM, Hijazi OM. Impact of chylothorax on the early post operative outcome after pediatric cardiovascular surgery. J Saudi Heart Assoc 2014;26:87-92.

Jenkins KJ, Gauvreau K, Newburger JW, Spray TL, Moller JH, Iezzoni LI. Consensus-based method for risk adjustment for surgery for congenital heart disease. J Thorac Cardiovasc Surg 2002;123:110-118.

Kara H, Uzun K, Bozok S. Tension chylothorax after coronary artery bypass grafting surgery. Turk J Thorac Cardiovasc Surg 2014;22:419-422.

Keceligil HT, Bahcivan M, Demirag MK. Treatment of persistent 
chylothorax with somatostatin. A case report. Chirurgia 2005;18:409-410.

Liu CS, Tsai HL, Chin TW, Wei CF. Surgical treatment of chylothorax caused by cardiothoracic surgery in children. J Chin Med Assoc 2005;68:234-236.

Merrigan BA, Winter DC, O'Sullivan GC. Chylothorax. Br J Surg 1997;84:15-20.

Nair SK, Petko M, Hayward MP. Aetiology and management of chylothorax in adults. Eur J Cardiothorac Surg 2007;32:362-369.

Nath DS, Savla J, Khemani RG, Nussbaum DP, Greene CL, Wells WJ. Thoracic duct ligation for persistent chylothorax after pediatric cardiothoracic surgery. Ann Thorac Surg 2009;88:246-251.

Oishi H, Hoshikawa Y, Sado T, Watanabe T, Sakurada A, Kondo T, Okada Y. A case of successful therapy by intrapleural injection of fibrin glue for chylothorax after lung transplantation for lymphangioleiomyomatosis. Ann Thorac Cardiovasc Surg 2017;20:40-44.

Sapmaz E, Karataş O, Iş̧ı H. Right chylothorax after thoracic sympathicotomy: A very rare case. Turk J Thorac Cardiovasc Surg 2018;26:484-486.

Sersar SI. Predictors of prolonged drainage of chylothorax after cardiac surgery: Single centre study. Pediatr Surg Int 2011;27:811-815.

Stenzl WStenzl W, Rigler B, Tscheliessnigg KH, Beitzke A, Metzler H. Treatment of postsurgical chylothorax with fibrin glue. Thorac Cardiovasc Surg 1983;31:35-36.

Tatar T, Kilic D, Ozkan M, Hatipoglu A, Aslamaci S. Management of chylothorax with octreotide after congenital heart surgery. Thorac Cardiovasc Surg 2011;59:298-301.

Yeh J, Brown ER, Kellogg KA, et al. Utility of a clinical practice guideline in treatment of chylothorax in the postoperative congenital heart patient. Ann Thorac Surg 2013;96:930-936.

Yıldız O, Öztürk E, Fırat Altın H, Ayyıldız P, Kasar T, İrdem A, et al. Chylothorax following pediatric cardiac surgery. Turk J Thorac Cardiovasc Surg 2015;23:434-440. 